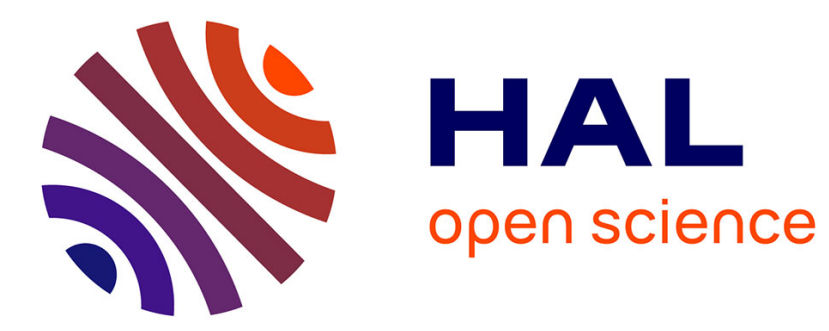

\title{
Regulation of a Drosophila cGMP-PDE by prenylation and interaction with a prenyl-binding protein
}

Jonathan P Day, Vaughn Cleghon, Miles Douglas Houslay, Shireen A. Davies

\section{To cite this version:}

Jonathan P Day, Vaughn Cleghon, Miles Douglas Houslay, Shireen A. Davies. Regulation of a Drosophila cGMP-PDE by prenylation and interaction with a prenyl-binding protein. Biochemical Journal, 2008, 414 (3), pp.363-374. 10.1042/BJ20080560 . hal-00478997

\section{HAL Id: hal-00478997 https://hal.science/hal-00478997}

Submitted on 30 Apr 2010

HAL is a multi-disciplinary open access archive for the deposit and dissemination of scientific research documents, whether they are published or not. The documents may come from teaching and research institutions in France or abroad, or from public or private research centers.
L'archive ouverte pluridisciplinaire HAL, est destinée au dépôt et à la diffusion de documents scientifiques de niveau recherche, publiés ou non, émanant des établissements d'enseignement et de recherche français ou étrangers, des laboratoires publics ou privés. 


\title{
Regulation of a Drosophila cGMP-PDE by prenylation and interaction with a prenyl-binding protein
}

\author{
Jonathan P. DAY, Vaughn CLEGHON , Miles D. HOUSLAY2* and Shireen-A. DAVIES \\ Glasgow, Glasgow G12 8QQ, U.K \\ *To whom correspondence should be addressed (email m.houslay@bio.gla.ac.uk)

\section{Running head: Prenylation of cGMP-PDE in Drosophila}

Institute of Biomedical and Life Sciences, Divisions of Molecular Genetics, University of Glasgow, Glasgow G11 6NU, U.K, ${ }^{1}$ Cincinnati Children's Hospital Medical Center, Division of Developmental Biology, 3333 Burnet Ave, Cincinnati, Ohio 45229, ${ }^{2}$ Institute of Biomedical and Life Sciences, Division of Biochemistry and Molecular Biology, University of

Post-translational modification by isoprenylation is a pivotal process for the correct functioning of many signalling proteins. The Drosophila melanogaster cGMP-specific phosphodiesterase, DmPDE5/6, possesses a CaaX-box prenylation signal-motif, as do several novel cGMP-PDEs from insect and echinoid species. DmPDE5/6 is prenylated in vivo at Cys1128 and is localised to the plasma membrane when expressed in Drosophila S2 cells. Site-directed mutagenesis of the prenylated cysteine residue (C1128S-DmPDE5/6), pharmacological inhibition of prenylation or co-expression of the Drosophila prenyl-binding protein, $D m P r B P / \delta$, each alters the sub-cellular localisation of $D m P D E 5 / 6$. Thus prenylation constitutes a critical post-translational modification of DmPDE5/6 for membrane-targeting. Co-immunoprecipitation and sub-cellular fractionation experiments show that DmPDE5/6 interacts with $D m P r B P / \delta$ in Drosophila S2 cells. Transgenic lines allow targeted expression of tagged, prenylation deficient C1128S-DmPDE5/6 to Type I (principal) cells in Drosophila Malpighian tubules, an in vivo model for DmPDE5/6 function. In contrast to wild-type DmPDE5/6, which was exclusively associated with the apical membrane, the C1128S-DmPDE5/6 mutant form was located primarily in the cytosol, although some residual association occurred at the apical membrane. Despite the profound change in intracellular localisation of C1128S-DmPDE5/6, active transport of cGMP is affected the same as by $D m P D E 5 / 6$. This suggests that in addition to prenylation and interaction with $D m P r B P / \delta$, further functional membrane-targeting signals exist within DmPDE5/6.

Keywords: renal epithelium, Drosophila cGMP, PDE6, PDE5, prenylation, S2 cell

\section{INTRODUCTION}

The precise sub-cellular localisation of components of cell signalling networks which allows the spatiotemporal control of signalling is of major importance in biology [1, 2]. This is exemplified by signalling systems employing the cyclic nucleotides cAMP and cGMP. The local concentrations of cyclic nucleotides is controlled by the precise positioning within the cell of cyclases, that catalyse their formation [3, 4], and cyclic nucleotide phosphodiesterases (PDEs) that catalyse their degradation [5, 6]. Indeed, it has been shown recently that PDEs can be tethered to sub-cellular targets by exquisitely precise interactions $[7,8]$. The result is tight control of cyclic nucleotide regulated effector molecules such as cAMP or CGMP-dependent protein kinases [8-10]. Therefore, the sub-cellular localization of PDEs has fundamental consequences for cellular physiology.

Many of the proteins involved in signal transduction events undergo some form of post-translational lipid modification essential for their correct localisation and function, including $\mathrm{N}$-terminal myristoylation and C-terminal isoprenylation and palmitoylation [11, 12]. Proteins are traditionally thought to undergo 
isoprenylation at a consensus C-terminal CaaX-box motif, where $a$ is an aliphatic residue and $\mathrm{X}$ is any residue [13]. However, recent analysis suggests that certain, non-aliphatic residues can exist at position +1 after the conserved cysteine and that there is a clear preference for hydrophobic residues at position +3 [14]. Isoprenylation is thought to be an important mediator of protein-membrane interactions. For example, ablation of prenylation in the $\mathrm{H}-, \mathrm{N}$ - and K-Ras GTPase family, completely redistributes these membrane-bound proteins to the cytosol [15].

The mammalian, retinal cGMP-specific phosphodiesterase (PDE6) has been shown to undergo C-terminal isoprenylation at its alpha, beta and alpha' catalytic subunits [16-18]. The PDE6 alpha and alpha' subunits are modified by farnesyl lipids, whereas the beta subunit is modified by the addition of geranylgeranyl groups. Such modifications are apparently required for binding of these PDEs to rod outer segment membranes [18]. Several prenylated proteins including retinal PDE6 catalytic subunits, rhodopsin kinase (GRK1), and the small GTPases Ha-Ras and Rap, have been shown to bind to the prenyl binding protein $(\mathrm{PrBP} / \delta)$, formerly $\mathrm{PDE} \delta$, [19-21]. PrBP/ $\delta$ participates in the transport of PDE6 catalytic subunits and GRK1 from the ER, where prenylation occurs, to photoreceptor outer segments [22].

In the genetic model organism, Drosophila melanogaster, a close sequence and functional homologue of both vertebrate PDE5 [23] and PDE6 [24], DmPDE5/6, has been identified [25]. DmPDE5/6 is a high $\mathrm{K}_{\mathrm{m}}$ enzyme that specifically hydrolyses cGMP and is sensitive to the PDE5-selective inhibitors, sildenafil and zaprinast [26, 27]. DmPDE5/6 also contains a C-terminal CaaX-box prenylation motif [25]. In Drosophila, endogenous DmPDE5/6 expression has been documented in head and body [25]; as well as in the Malpighian (renal) tubule [28], a cGMP-modulated transporting epithelium that is critical for detoxification, osmoregulation and immunity. Recent work has demonstrated a novel role in the modulation of cGMP efflux by DmPDE5/6 in tubule [28].

Drosophila transgenics [29] allow a sophisticated system for ectopic over-expression or ablation of genes of choice in particular cell-types or tissues in the intact animal. Thus, the tubule provides a powerful in vivo model in which to assess regulation and function of novel cG-PDEs. We show that DmPDE5/6 is a prenylated enzyme which is a member of a family of PDE5-like enzymes with prenylation motifs. We also show that $D m P D E 5 / 6$ can associate with Drosophila prenyl binding protein $(D m P r B P / \delta)$, and show that the localisation of DmPDE5/6 in the tubule is altered when its prenylation is ablated.

\section{MATERIALS AND METHODS}

\section{Bioinformatics}

The amino acid sequences of Drosophila melanogaster PDE5/6 (DmPDE5/6 encoded by gene CG8279) homologues were identified by BLAST-searching the non-redundant peptide sequence database using DmPDE5/6 as the query sequence. Retrieved sequences were individually examined for the presence of putative CaaX-box prenylation motifs. Those sequences containing such motifs were subjected to further analysis using the PrePS prenylation prediction suite (http://mendel.imp.ac.at/sat/PrePS/index.html) [14]. Accession numbers of sequences were as follows: Drosophila pseudoobscura GA20950-XP_001358768, Anopheles gambiae AGAP004119-XP_312997, Apis mellifera XP_394107, Triboleum castaneum XP_967847, Strongylocentrotus pupuratus PDE5a-NP_001029121, Danio rerio XP_697567, Xenopus tropicalis PDE5a-NP_001072812, Homo sapiens PDE6A-P16499, Homo sapiens PDE6B-NP_000274, Homo sapiens PDE6C-P51160, Homo sapiens PDE5A1-NP_001074.2, Homo sapiens PDE11A4NP_058649.3, Drosophila melanogaster Ras85D-NP_476699. Alignment of the C-terminal 25 amino acids of selected proteins and sequence similarity trees were made using ClustalW (http://www.ebi.ac.uk/clustalw/), and drawn using BioEdit (http://www.mbio.ncsu.edu/ BioEdit/bioedit.html).

$D m P r B P / \delta$ (encoded by gene CG9296) was identified from Flybase, (http://flybase.bio.indiana.edu/.bin/fbidq.html?FBgn0032059).

Site-directed mutagenesis of PDE6. Targeted PCR mutagenesis of DmPDE5/6 cysteine 1128 to serine (to achieve DmPDE5/6 C1128S) was performed according to a commercial mutagenesis protocol (Stratagene). The DmPDE5/6 (CG8279) plasmid template was PCR amplified using primers (Suppl. 
Table 1) designed to achieve the TGC to AGC mutation, and to include complementary flanking sequences of $20 \mathrm{bp}$. Purified PCR products were digested with DpnI to remove template DNA, and $2 \mu \mathrm{l}$ of the digest was used to transform chemically competent DH5 $\alpha$ cells.

\section{Expression of DmPDE5/6 in Sf9 cells}

Recombinant baculovirus generation utilised the BaculoGold system (BD PharMingen). The open reading frames encoding wild-type DmPDE5/6 and DmPDE5/6 C1128S, tagged at the N-terminus with a V5epitope, were cloned into the baculovirus transfer vector pVL1393 (BD PharMingen) using the BamHI and NotI restriction sites, and plasmids purified. For all infections, a P2 recombinant viral stock, generated after two rounds of amplification via standard methods was used. For protein expression, $5 \mathrm{x}$ $10^{6} \mathrm{Sf9}$ cells at exponential growth were plated into $75 \mathrm{~cm}^{2}$ cell culture flasks in $9 \mathrm{ml}$ of medium. $0.5 \mathrm{ml}$ of P2 viral stock was added and cells were incubated at $27^{\circ} \mathrm{C}$ for $36 \mathrm{~h}$. Cells were harvested by centrifugation at 2,000 $\mathrm{g}$ for $5 \mathrm{~min}$, the supernatant discarded and the cell pellet was used either for labelling experiments or for PDE assays.

\section{In vitro prenylation experiments}

Three aliquots of $5 \times 10^{6} \mathrm{Sf9}$ cells were plated into $75 \mathrm{~cm}^{2}$ cell culture flasks in $10 \mathrm{ml}$ of media and allowed to adhere for $30 \mathrm{~min}$ before addition of $0.5 \mathrm{ml}$ of recombinant viral stock.

Infection was allowed to proceed for 24 hours before addition of Mevinolin (Sigma) $(40 \mu \mathrm{mol} / \mathrm{l})$ for $1 \mathrm{~h}$, after which cells were centrifuged and resuspended in $2 \mathrm{ml}$ of medium. Cells were then incubated for $16 \mathrm{~h}$ in $25 \mu \mathrm{Ci} \mathrm{ml}{ }^{-1}\left[5-{ }^{3} \mathrm{H}\right]$ mevalonic acid (39 Ci/mmol, Sigma) and then harvested, washed once in PBS, and pelleted by centrifugation at $1,500 \mathrm{~g}$ for $2 \mathrm{~min}$. The pellet was lysed in $200 \mu \mathrm{l}$ of 3T3 lysis buffer ( $25 \mathrm{mM}$ HEPES, pH 7.4, $50 \mathrm{mM} \mathrm{NaCl}, 10 \%$ glycerol, 1\% Triton X100) and the protein concentration measured. $70 \mu \mathrm{g}$ of protein was removed for Western analysis and DmPDE5/6 was immunoprecipitated from the remaining protein sample with purified polyclonal anti-DmPDE5/6 antibody using standard procedures [25]. The protein A beads were boiled in $10 \mu \mathrm{l}$ of SDS loading buffer and used to load two $10 \%$ SDS PAGE gels. One gel was run for Western analysis and loaded with $10 \mu \mathrm{g}$ of total protein, or $3 \mu \mathrm{l}$ of immunoprecipitated protein sample per lane; and the other was used for fluorography and loaded with 60 $\mu \mathrm{g}$ of total protein and the remainder $(20 \mu \mathrm{l})$ of the precipitated protein per lane. The gel for fluorography was treated with Enlight (Mo Bi Tec Molecular BioTechnology) for $1 \mathrm{~h}$, dried and fluorographed at $-70^{\circ} \mathrm{C}$ for $1-4$ weeks. The gel for Western blotting was processed as described below.

\section{Cloning and expression of DmPDE5/6, DmPDE5/6 C1128S, DmRas85D and $D m P r B P / \delta$ in Drosophila S2 cells}

In order to generate V5-epitope tagged proteins, $D m P D E 5 / 6$ cloned as described in [25] and $D m P r B P / \delta$ were cloned into the S2 vector, pMT/V5-HIS-TOPO (Invitrogen). For cloning of Drosophila Ras85D, the Ras85D gene was amplified from an EST (RE53955) obtained from the Berkeley Drosophila Genome Project (BDGP, http://www.fruitfly.org/EST/index.shtml) using forward primer (incorporating a BglII restriction site) and reverse primer (incorporating a NotI restriction site). In order to generate GFP-tagged Ras85D, the coding sequence for enhanced green fluorescent protein was PCR-amplified (forward primer: incorporating a BamHI restriction site and optimal Kozak sequence (ACCATGG); reverse primer: incorporating a BamHI restriction site), digested and cloned at the 5' end of Ras85D using the BglII restriction site. The resulting construct was cloned into pMT/V5-HIS-TOPO vector. The open reading frame of $\mathrm{DmPrBP} / \delta$ was PCR amplified from genomic DNA template using a reverse primer omitting the stop codon, and directly cloned into pMT/V5-HIS-TOPO (Invitrogen). For co-localisation of DmPDE5/6 with $D m P r B P / \delta$ a pMT GFP:DmPDE5/6 was generated by inserting the EGFP coding sequence at the 5' end of the DmPDE5/6 open reading frame. These plasmids were then used for the transient transfection of $\mathrm{S} 2$ cells under conditions of $\mathrm{Cu}^{2+}$-inducible expression. Cells were cultured according to standard protocols [30]. Approximately $3 \times 10^{6}$ cells were used in each transfection, performed using Cellfectin (Invitrogen); transfection efficiencies were routinely 10-25\%. 


\section{Fractionation experiments}

Cellular fractionation was carried out on approximately $3 \times 10^{6}$ transiently transfected S2 cells. After harvesting and washing, cells were lysed by incubation on ice for $10 \mathrm{~min}$ in $80 \mu \mathrm{l}$ ice-cold hypotonic buffer (10 mM Tris-HCl pH 7.5, $5 \mathrm{mM} \mathrm{MgCl}$, 1mM DTT, 1:100 dilution of protease inhibitor cocktail (Sigma)) and then passed through a fine gauge needle 10 times. The homogenate was then adjusted to 0.2 $\mathrm{M}$ sucrose by addition of a $1 / 10^{\text {th }}$ volume of $2 \mathrm{M}$ sucrose solution and subjected to 10 min centrifugation at $1,000 \mathrm{~g}$ at $4{ }^{\circ} \mathrm{C}$. The pellet was retained as the $\mathrm{P} 1$ fraction, and supernatant removed to a fresh tube and centrifuged for $10 \mathrm{~min}$ at $15,000 \mathrm{~g}$ at $4{ }^{\circ} \mathrm{C}$. The resulting pellet was retained as the $\mathrm{P} 15$ fraction, and supernatant removed to a fresh tube and centrifuged for $30 \mathrm{~min}$ at $100,000 \mathrm{~g}$ at $4{ }^{\circ} \mathrm{C}$ to yield the P100 fraction. The supernatant was retained as the S100 fraction. Pellets were washed once in sucrose buffer and resuspended in $88 \mu \mathrm{l}$ detergent buffer (50 mM Tris-HCl, 2\% IGEPAL (Sigma), pH 7.5) and $20 \mu \mathrm{l}$ each of supernatant and resuspended pellets were analysed by Western blotting.

\section{Western blotting}

Tubule or cell samples were homogenised, on ice, in 3T3 lysis buffer with protease inhibitor cocktail (Sigma). Typically, $20 \mu \mathrm{g}$ of protein samples were separated using SDS PAGE, on 10\% gels. Western blotting was carried out using the ECL ${ }^{\mathrm{TM}}$ Western Blotting analysis system (Amersham Pharmacia) according to standard protocols using either a 1:5000 dilution of anti-V5 antibody (Invitrogen) followed by a 1:5000 dilution of anti-mouse secondary antibody (Amersham BioSciences) [31] ; or using a monoclonal anti-GFP antibody (Zymed) at 1:1000 dilution.

\section{Immunocytochemistry and confocal microscopy}

Immunocytochemistry of S2 cells was carried out according to standard protocols [31] using cells immobilised on poly-L-lysine coated coverslips. Samples were processed and treated with a 1: 1000 dilution of anti-V5 primary antibody (Invitrogen), with secondary staining using anti-mouse FITC, 1:500 (Jackson Laboratories) or anti-mouse Texas Red, 1:500 (AbCam). Cell nuclei were stained with DAPI (4', 6'-diamidino-2-phenylindole hydrochloride) at $1 \mu \mathrm{g} / \mathrm{ml}$. The coverslips to which samples were attached were then mounted on slides using Vectashield mounting medium (Vector Laboratories) and sealed with glycerol-gelatin.

Tubules expressing GFP:DmPDE5/6 or GFP:C1128S-DmPDE5/6 in principal cells were dissected in Schneider's medium and mounted on poly-L-lysine coated slides. Tubules were fixed and permeabilised as previously described [32] and incubated for $1 \mathrm{~h} \mathrm{in} 1 \mathrm{mg} / \mathrm{ml}$ Texas Red-conjugated phalloidin (Sigma)an F-actin stain indicative of tubule apical membrane [33]- in Phosphate-buffered saline/ $0.3 \% \mathrm{v} / \mathrm{v}$ Triton. After washing, tubules were DAPI-stained as above. Slides were mounted in Vectashield. Samples were imaged using a Zeiss 510 Meta coupled to an inverted Zeiss microscope using a $405 \mathrm{~nm}$ Diode laser / 420-480 nm band pass filter for DAPI, HeNe1 $543 \mathrm{~nm}$ laser / 561-754 nm band pass filter for Texas Red, and an Argon 488 nm laser / 505-550 nm band pass filter for FITC.

\section{Generation of transgenic lines}

The sequence for C1128S-DmPDE5/6 was sub-cloned into pPmt vector [34] and used to transform Drosophila embryos according to standard techniques as previously described [35]. This allows chromosomal insertion of a UAS-GFP:C1128S-DmPDE5/6 transgene in transformed embryos.

\section{Drosophila stocks}

All strains were maintained on standard Drosophila diet at $25^{\circ} \mathrm{C}$ and $55 \%$ humidity, on a $12: 12$ photoperiod. Drosophila lines used in this study were: $w^{1118}$ (parental strain used for transformation of embryos); UAS-GFP:DmPDE5/6 (allows targeted expression of GFP-tagged DmPDE5/6, [28]); UASGFP:C1128S-DmPDE5/6 (transgenic lines generated for this study, allows targeted expression of GFPtagged DmPDE5/6 C1128S); c42: GAL4 enhancer trap line, used to drive expression of UAS constructs in 
only tubule principal cells $[35,36]$. The following lines were also used, which were the progeny of crosses between c42 and specific UAS transgenic lines: c42/UAS-GFP:DmPDE5/6; c42/UASGFP:C1128S-DmPDE5/6. Adults were used at 7 days post-emergence for all experiments.

\section{cG-PDE assays}

Assays for cG-PDE in tubules were performed as previously described [25, 37] using 200 tubules ( $\sim 40 \mu \mathrm{g}$ protein) for each sample, homogenised and assayed in $37 \mathrm{MBq} / \mathrm{ml}$ tritiated cGMP or cAMP (Amersham Biosciences) in $50 \mu \mathrm{l}$ KHEM buffer ( $50 \mathrm{mM} \mathrm{KCl,} 10 \mathrm{mM}$ EGTA, $1.92 \mathrm{mM} \mathrm{MgCl}$, $1 \mathrm{mM}$ dithiothreitol (DTT), $50 \mathrm{mM}$ HEPES, pH 7.4, $1 \mu$ l Sigma P8340 protease inhibitor cocktail). A final substrate concentration of $10 \mu \mathrm{M}$ cGMP was used in tubule reactions, as endogenous Drosophila cG-PDEs are high $\mathrm{K}_{\mathrm{m}}$ enzymes [25]. $\mathrm{K}_{\mathrm{m}}$ and relative $\mathrm{V}_{\max }$ values of DmPDE5/6 and C1128S-DmPDE5/6 expressed in Sf9 cells were determined by carrying out western analysis of lysates and adjusting the amount of protein used so that equal amounts of DmPDE5/6 was added to each cG-PDE reaction. cG-PDE assays were carried out on these samples at 1, 2, 5, 10, 20, 50 and $100 \mu \mathrm{M}$ cGMP final substrate concentration. Final PDE activity was expressed as pmol or nmol cGMP hydrolysed per min per mg of protein.

\section{cGMP transport assays}

Transport assays were based on methodology for ouabain transport [38] and performed according to previously published protocols [28]. Malpighian tubules from seven day old adult flies were set up as for a standard fluid transport assay, as previously described [25]. Experiments were carried out at $100 \mu \mathrm{M}$ cGMP in the presence of $0.2 \mu \mathrm{Ci}$ of tritiated cGMP (Amersham BioSciences). Tubules were allowed to secrete for $1 \mathrm{~h}$ and diameters of the secreted droplets measured. Secreted droplets, and a $1 \mu \mathrm{l}$ aliquot of each bathing droplet were then removed to Eppendorf tubes containing scintillation fluid. The rate of cGMP transport, in $\mathrm{fmol} / \mathrm{min}$, was calculated by using the equation: Rate $=\mathrm{S}[$ substrate $] / \mathrm{B} t$; where $S=$ counts in the secreted drop $(\mathrm{cpm})$, substrate $=\mathrm{cGMP}$ concentration $(\mu \mathrm{M}), B=$ counts in the bathing drop $(\mathrm{cpm}), t=$ time $(\mathrm{min})$. The transport ratio was calculated by dividing the concentration of $\left[{ }^{3} \mathrm{H}\right] \mathrm{cGMP}$ in the secreted droplet by the concentration of $\left.{ }^{3} \mathrm{H}\right]$ cGMP in the bathing droplet. These experiments were performed on tubules from UAS-GFP:C1128S-DmPDE5/6 and c42/UAS-GFP:C1128S-DmPDE5/6. Data for DmPDE5/6 transgenic tubules published in [28]. Results are expressed as units of either rate of transport (pmol cGMP/min) or transport ratio \pm SEM, $N=12$.

\section{Statistics}

Where appropriate, statistical significance was assessed using Student's $t$-test for unpaired samples, taking $\mathrm{p}<0.05$ as the critical value.

\section{RESULTS}

\section{DmPDE5/6 is prenylated at a C-terminal CaaX-box}

The intracellular targeting of PDEs underpins the generation of intracellular gradients, pools and sinks for cyclic nucleotides, thus providing a critical factor in the regulation of cyclic nucleotide signalling $[8,9]$. In a number of systems, prenylation has been shown to provide an important means of regulating the intracellular distribution of signalling molecules by conferring membrane association [12]. To date, however, the catalytic subunits of mammalian PDE6, which are found exclusively in the visual system [39], provide the only PDE for which prenylation has been demonstrated. However, the C-terminus of DmPDE5/6 contains a CaaX-box motif of a form such that might be predicted to be modified by the addition of an isoprenyl lipid (Figure 1A and [25]).

We also investigated the possibility that other non-retinal cGMP-PDEs might have CaaX-box prenylation motifs. Database searches were performed, using DmPDE5/6 as a query sequence. The results from this bioinformatics analysis revealed the presence of several further putative cGMP-PDEs that contain possible CaaX-box motifs (Figure 1A). Alignment of these novel sequences with mammalian PDEs showed that they are more closely related to mammalian PDE5 or PDE11 than the retinal PDE 
catalytic subunits (Figure 1B and Table 1). We noted that six out of seven of the putative CaaX-boxes contained non-consensus sequences, particularly at the +1 and +3 positions with respect to the conserved cysteine (Figure 1A). To investigate whether these sequences could be functional CaaX-boxes, each putative PDE was submitted for analysis by the prenylation prediction suite (PrePS, http://mendel.imp.univie.ac.at/sat/PrePS). This analysis suggested that DmPDE5/6, D. pseudoobscura GA20950, A. gambiae AGAP004119 and T. castaneum XP_967847 are likely substrates for geranylgeranyl transferase 1 (GGT1), whereas A. mellifera XP_394107 and S. purpuratus PDE5a [40] are likely substrates for farnesyl transferase (FT) (Table 1). The novel putative vertebrate cGMP-PDEs, $D$. rerio XP_697567 and $X$. tropicalis PDE5a, were not predicted to undergo prenylation using this algorithm (Table 1).

In order to gain insight into the importance of the CaaX-box for the prenylation of $\mathrm{DmPDE} 5 / 6$, the putative prenylated cysteine 1128 was mutated to the conservative serine (C1128S). Radio-labelling experiments allowed us to demonstrate post-translational isoprenylation of DmPDE5/6 in vivo. Incubation of cells with tritiated mevalonic acid $\left({ }^{3}[\mathrm{H}]\right.$ MVA), the precursor to isoprenyl pyrophosphate, has been shown to specifically label prenylated proteins [41]. To increase the sensitivity of labelling, the synthesis of iso-prenyl groups from endogenous mevaldate was inhibited by the addition of mevinolin, a 3Hydroxy-3-methylglutaryl-CoA reductase (HMG-CoA) inhibitor, prior to the addition of [ $\left.{ }^{3} \mathrm{H}\right] \mathrm{MVA}$ [41]. The Sf9 cell expression system has previously been shown to result in high levels of correctly modified retinal PDE6 subunits [18] and was used here to produce sufficient V5-tagged DmPDE5/6 and C1128SDmPDE5/6 protein for labelling experiments (Figure 2A).

Western analysis of cell lysates prepared from DmPDE5/6 or C1128S-DmPDE5/6 infected Sf9 cells (pre-treated with mevinolin, and labelled with $\left[{ }^{3} \mathrm{H}\right] \mathrm{MVA}$ ) with anti-V5 antibody shows that DmPDE5/6 and C1128S-DmPDE5/6 constructs are expressed at the anticipated size, $130 \mathrm{kDa}$ (Figure 2A, lanes 1 and 2). Immunoprecipitation of cell lysates with anti-DmPDE5/6 antibody [25] increases the amount of DmPDE5/6 and C1128S-DmPDE5/6 proteins (Figure 2A, lanes 4 and 5). Control (uninfected) cell lysates show no immunoreactive species on the Western blot (Figure 2A, lanes 3 and 6).

Corresponding results from SDS-PAGE and autofluorograph analysis (Figure 2B) shows the presence of radio-labelled protein of $130 \mathrm{kDa}$ corresponding to DmPDE5/6 (Figure 2B, lane 1) but not to C1128S-DmPDE5/6 (Figure 2B, lane 2). No $130 \mathrm{kDa}$ protein is detected in control cell extract although there is labelling of endogenous 30 and $60 \mathrm{kDa}$ proteins (Figure 2B, lane 3). Immunoprecipitation of DmPDE5/6 amplifies the signal compared to total lysate and confirms that DmPDE5/6 is radio-labelled with MVA (Figure 2B, lane 4); MVA is not incorporated into C112S-DmPDE5/6-expressing cells or control, uninfected cells (Figure 2B, lanes 5 and 6). Taken together, these results show that DmPDE5/6 undergoes post-translational processing, via the attachment of an isoprenyl group at cysteine 1128 of the C-terminal CaaX-box.

Catalytic properties of DmPDE5/6 and the prenylation-deficient C1128S-DmPDE5/6

Both DmPDE5/6 and C1128S-DmPDE5/6 produced by expression in Sf9 cells display similar $\mathrm{K}_{\mathrm{m}}$ values for cGMP hydrolysis (C1128S-DmPDE5/6: $35.4 \pm 1.2 \mu \mathrm{M}$ vs DmPDE5/6: $28.1 \pm 1.4 \mu \mathrm{M}$ ) (Figure 2C). However, DmPDE5/6 was found to have a relative $\mathrm{V}_{\max }$ for cGMP hydrolysis approximately 2.2 times greater than that of C1128S-DmPDE5/6 (Figure 2C).

\section{Disruption of prenylation alters sub-cellular distribution of DmPDE5/6 and Ras85D in S2 cells}

In order to investigate potential alterations in the sub-cellular localisation of DmPDE5/6 upon ablation of prenylation, V5 epitope-tagged DmPDE5/6 and C1128S-DmPDE5/6 constructs were transfected into Drosophila S2 cells. Wild-type DmPDE5/6 is localised to the plasma membrane (Figure 3A). In contrast to this, C1128S-DmPDE5/6 is distributed throughout the cytoplasm (Figure 3B). In order to determine if the altered distribution was due to removal of prenylation rather than simply mutation of Cys1128 per se, we treated S2 cells expressing wild-type DmPDE5/6 with the geranylgeranyl transferase inhibitor 286 (GGTI-286) $(1 \mu \mathrm{M})$ [42]. This resulted in re-distribution of DmPDE5/6 throughout the cytoplasm (Figure 3C), indicating that prenylation is required for plasma membrane targeting in S2 cells. 
The sub-cellular localisation of DmPDE5/6 and C1128S-DmPDE5/6 was also assessed by subcellular fractionation. Lysed S2 cells were separated into cytosolic and particulate fractions using centrifugation, followed by detection of DmPDE5/6 through western blotting. DmPDE5/6 was found predominantly in the particulate P15 fraction (Inset, Figure 3A). By contrast, prenyl-deficient C1128SDmPDE5/6 was found predominantly in the soluble S15 fraction (Inset, Figure 3B). Consistent with confocal immunohistochemical analyses, treatment of transfected S2 cells with GGTI-286 resulted in wild-type DmPDE5/6, now being predominantly localised in the S15 fraction (Inset, Figure 3C). Two bands corresponding to DmPDE5/6 are present in the soluble fraction in Figure 3B and 3C. The lower apparent molecular weight species may represent proteolytic fragments of non-prenylated DmPDE5/6. Alternatively, the different bands may correspond to distinct phosphorylation states of the enzyme.

To confirm that the Drosophila S2 cell line is a useful system to analyse the sub-cellular localisation of prenylated proteins, we expressed GFP-tagged Drosophila Ras85D, a protein known to undergo lipid modification [43, 44]. Indeed, in all mammalian Ras isoforms, mutation of the putative prenylated cysteine to serine has been shown to prevent the attachment of the isoprenyl group. Drosophila Ras85D encodes a C-terminal CaaX-box ending in leucine, with a proximal polybasic region (Figure 1A), suggesting that Drosophila Ras is a canonical prenylated protein. Confocal analysis shows that GFP-tagged Drosophila Ras localises to the plasma membrane with staining of intracellular vesicles and fainter staining of the peri-nuclear region when expressed in Drosophila S2 cells (Figure 3D). Furthermore, treatment of GFP-Ras85D expressing cells with $1 \mu$ M GGTI-286 resulted in re-distribution of GFP-Ras85D throughout the cytoplasm (Figure 3E). These data provide strong evidence that Ras85D undergoes prenylation in S2 cells and that pharmacological inhibition of this process alters its sub-cellular localisation. Furthermore, this suggests that Drosophila S2 cells constitute a useful model for studies of prenylated proteins.

Fractionation experiments confirmed the redistribution of Ras85D in S2 cells after GGTI-286 treatment. GFP-Ras85D is evenly distributed between the insoluble and soluble fractions (Inset, Figure 3D). However, pre-treatment of S2 cells with GGTI-286 completely re-localises Ras85D to the soluble S15 fraction (Inset, Figure 3E).

\section{DmPrBP/ $\delta$ modulates localisation of $D m P D E 5 / 6$ in Drosophila}

Given that retinal PDE6 interacts with $\mathrm{PrBP} / \delta$, and that $D m P D E 5 / 6$ does undergo prenylation in vivo, we investigated the existence of a $\mathrm{PrBP} / \delta$ homologue in Drosophila; and the possibility that $D m P D E 5 / 6$ might interact with $D m \operatorname{PrBP} / \delta$. $D m \mathrm{PrBP} / \delta$ is a polypeptide of 151 amino acids, encoded by gene CG9296 (http://flybase.bio.indiana.edu/reports/FBgn0032059.html). Alignment with mammalian prenylbinding proteins shows that the CG9296 gene product is highly similar to both human and mouse $\mathrm{PrBP} / \delta$, with $61 \%$ identity and $78 \%$ similarity over the entire polypeptide sequence, to human $\mathrm{PrBP} / \delta$ [20]. When expressed in S2 cells, $D m P r B P / \delta$ is targeted predominantly to the nucleus with less intense staining in the cytoplasm (Figure 4A). Fractionation followed by western blotting shows that $D m P r B P / \delta$ is predominantly soluble (Inset Figure 4A). To determine if $D m P D E 5 / 6$ and $D m P r B P / \delta$ interact in vivo, GFP-tagged $D m P D E 5 / 6$ and V5-tagged $D m P r B P / \delta$ were transfected into S2 cells and their sub-cellular localisation was ascertained by confocal microscopy. Strikingly, when DmPDE5/6 is co-transfected with $D m P r B P / \delta$, the localisation of $D m P D E 5 / 6$ is altered from the plasma membrane to predominantly intracellular (compare Figure 3A with Figure 4Bi). Indeed, in co-transfection studies the sub-cellular location of $D m P D E 5 / 6$ now coincides with that of $D m P r B P / \delta$ (Figure 4Biii), suggesting that $D m P D E 5 / 6$ has been sequestered to $D m P r B P / \delta$. Although, these data suggest that $D m P r B P / \delta$ provides the dominant intracellular localisation signal, it seems that DmPDE5/6 is not without effect on the localisation of $D m P r B P / \delta$. Thus, in this regard, the nuclear localisation of $D m P r B P / \delta$ appears to be compromised when it is co-expressed with DmPDE5/6 compared to when it is expressed alone (contrast Figure 4Bii to figure $4 \mathrm{~A})$.

In order to confirm that $D m P D E 5 / 6$ and $D m P r B P / \delta$ can exist in the same complex, coimmunoprecipitation was performed. DmPDE5/6 and $D m P r B P / \delta$ were co-transfected into S2 cells and 
DmPDE5/6 was immunoprecipitated with a poly-clonal DmPDE5/6 antibody [25]. Western blotting of the immunoprecipitates confirmed that $\mathrm{DmPrBP} / \delta$ interacts with $D m P D E 5 / 6$ (Figure 4C).

To further confirm that interaction with $\mathrm{DmPrBP} / \delta$ altered $D m P D E 5 / 6$ intracellular localisation, sub-cellular fractionation was undertaken. S2 cells were transfected with either V5-tagged DmPDE5/6 or V5-tagged $D m P r B P / \delta$ alone or co-transfected with both proteins, lysed and then separated using differential centrifugation (Figure 5A). The collected fractions were then analysed by western blotting. When expressed alone, DmPDE5/6 was found predominantly in the particulate P1 fraction (Figure 5B), whereas $\mathrm{DmPrBP} / \delta$ expressed alone resided mainly in the soluble S100 fraction (Figure 5C). In contrast to this, when co-expressed with $D m P r B P / \delta, D m P D E 5 / 6$ occurred mainly in the microsomal P100 fraction (Figure 4D, $130 \mathrm{kDa}$ species). Consistent with the confocal immunohistochemical studies, $\mathrm{DmPrBP} / \delta$ showed a change in localisation when co-expressed with DmPDE5/6, becoming evenly distributed between the P1, P100 and S100 fractions (Figure 5D, 22 kDa species).

\section{Localisation of C1128S-DmPDE5/6 is disrupted in vivo}

In order to gain insight into the role of prenylated DmPDE5/6 in vivo, the Drosophila Malpighian (renal) tubules were utilised as an organotypic screen for DmPDE5/6 function. Previous work demonstrated that DmPDE5/6 is endogenously expressed in tubules [28]. Furthermore, generation of transgenic flies expressing N-terminal GFP-tagged DmPDE5/6 showed that DmPDE5/6 is localised to the apical membrane of principal cells in tubules [28].

In this study, a UAS transgenic line was generated (GFP:C1128S-DmPDE5/6), which allowed targeted expression of GFP-tagged, prenylation-deficient C1128S-DmPDE5/6 in specific cell-types via GAL4 enhancer-trap drivers. Specific expression of GFP-tagged C1128S-DmPDE5/6 in tubule principal cells is effectively achieved using the c42 GAL4 driver [35, 36]. In c42/GFP: C1128S-DmPDE5/6 tubules, staining is mostly observed in the cytoplasm (Figure 6A) compared to GFP:DmPDE5/6 staining, which is located in the apical membrane (Figure 6B and [28]), as indicated by co-localisation with the apical membrane marker, F-actin [33]. However, it is also apparent that a fraction of C1128S-DmPDE5/6 is able to associate with the apical membrane (Fig. 6A). This is supported by fractionation studies (Figure 3), where ablation of prenylation via the C1128S mutation does not completely remove DmPDE5/6 from the membrane to the cytosolic fraction of S2 cells. These data indicate that whilst prenylation provides a major membrane targeting signal there are undoubtedly additional, independent signals that are involved in driving the specific localisation of DmPDE5/6 to the apical membrane.

\section{C1128S-DmPDE5/6 retains biological activity}

Tubules expressing C1128S-DmPDE5/6 in the principal cells have significantly increased cGMPPDE activity compared to control tubules, showing that the transgene is an active cG-PDE in vivo (Figure $6 C)$. cGMP-PDE activity is significantly reduced compared to that observed with the transgene encoding wild-type GFP-tagged DmPDE5/6. This may be due to lower expression levels (Figure 6D) and/or the lower $\mathrm{V}_{\max }$ of C1128S-DmPDE5/6 (Figure 2C) compared to wild-type. Previous work has shown that DmPDE5/6 directly modulates transport of cGMP (efflux) by the tubule [28]: targeted over-expression of DmPDE5/6 inhibits rates of cGMP efflux, while targeted knock-down via RNAi significantly increases cGMP efflux. Expression of C1128S-DmPDE5/6 in principal cells also inhibits cGMP transport rate and ratio (figure 6E and 6F), and to the same extent as that induced by DmPDE5/6 over-expression (figure 6G and $6 \mathrm{H})$.

\section{DISCUSSION}

The precise targeting of PDEs to specific sub-cellular locations provides a mechanism for the spatiotemporal control of cyclic nucleotide-mediated signalling events [6, 45, 46] . Prenylation is a lipid posttranslational modification that works synergistically with a second signal to promote the membraneassociation and, consequently, the biological activity of many proteins [47]. For example, prenylation of 
the small GTPase, Ras, is essential for both its membrane-binding and transforming activity [43]. In the mammalian retina, prenylation of the catalytic PDE subunits is required for their binding to rod outer segment membrane and, by inference, effective control of cGMP-mediated visual signal transduction [17]. We show here that Drosophila melanogaster PDE5/6 undergoes isoprenyl post-translational modification at its C-terminal CaaX-box motif. This is the first non-retinal PDE for which such modification has been demonstrated.

In addition to DmPDE5/6, we have identified a number of putative non-retinal cGMP-PDEs that contain CaaX-box motifs and are predicted to undergo prenylation, suggesting that prenylation may be a conserved feature important for their function. Of these, functional data is only available for Strongylocentrotus purpuratus PDE5 (suPDE5), a cGMP-PDE involved in sperm motility that is regulated by phosphorylation and $\mathrm{pH}$ changes [40]. The presence of a CaaX-box motif within suPDE5 suggests prenylation may represent another form of regulation for this enzyme. It will be of interest to determine if suPDE5 is indeed prenylated in vivo.

Two putative CaaX-box containing PDE sequences, Xenopus tropicalis PDE5a and Danio rerio XP_697567, have C-terminal regions divergent from that of DmPDE5/6. Analysis by the PrePS prenylation prediction software (http://mendel.imp.ac.at/sat/PrePS/index.html) suggested that neither $X$. tropicalis PDE5a nor D. rerio XP_697567 undergo prenylation in vivo, due to the presence of unfavourable residues in the +1 to +3 positions after the conserved cysteine. However, we also noted, using the same software, that D. melanogaster Ras85D was predicted not to be a substrate for either GGT1 or FT, although our data clearly demonstrate a change in localisation of Ras upon treatment of cells with GGTI-286 (Figure 3D and 3E). This may reflect the relative paucity of published data regarding prenylated Drosophila proteins that is available for database compilation, suggesting that there is scope for prenylation in vivo of even unfavourable substrates.

Site-directed mutagenesis of the conserved CaaX-box cysteine (C1128S) in DmPDE5/6 ablates prenylation and modifies localisation of DmPDE5/6 to the cytoplasm in S2 cells. However, sub-cellular fractionation of S2 cells reveals that a significant proportion of C1128S-DmPDE5/6 remains in the insoluble fraction. In addition to this, C1128S-DmPDE5/6 still shows partial association with the apical membrane when expressed in tubule principal cells. Therefore, removal of DmPDE5/6 prenylation is not sufficient to completely disrupt its localisation. This suggests that whilst prenylation forms an important part of the localisation machinery for DmPDE5/6, additional motifs are required for the fidelity of DmPDE5/6 targeting. Indeed, in many proteins multiple signals are required for efficient targeting to membranes and to signalling complexes[7, 15, 48, 49] This may involve multiple lipid modifications or multiple sites of protein interaction. For example, K-Ras requires both farnesylation and a polybasic region for efficient membrane targeting [15]. However, unlike DmPDE5/6, removal of K-Ras prenylation renders this protein completely soluble [15], suggesting that the targeting sequences for DmPDE5/6 are more complex than for K-Ras. Interestingly, both positive and negative plasma-membrane targeting sequences have been found within the palmitoylated G-protein coupled receptor kinase 6A (GRK6A) [48]. It is plausible that additional sequences facilitating plasma-membrane localisation operate within DmPDE5/6.

The fractionation experiments (figure 3) reveal that two bands corresponding to prenylationinhibited, wild-type DmPDE5/6 and C1128S-DmPDE5/6 are present in the cytosolic fractions. The lower apparent molecular weight species may represent proteolytic fragments of non-prenylated DmPDE5/6, suggesting that non-prenylated DmPDE5/6 may be more prone to degradation than the wild-type enzyme. Alternatively, the different bands may correspond to distinct phosphorylation states of the DmPDE5/6. This raises the intriguing possibility that prenylation may either protect DmPDE5/6 from phosphorylation by preventing access of a cytosolic kinase or promote phosphorylation by localising DmPDE5/6 to a site where an active kinase resides. Further work will be required to distinguish between these possibilities.

Whilst we could not identify the species of prenyl group that modifies DmPDE5/6, we consider it likely that DmPDE5/6 is modified with a geranylgeranyl group for two reasons. Firstly, the C-terminal amino acid of the DmPDE5/6 CaaX-box is leucine, which normally serves as substrate for GGTPase1 [50]. Secondly, we have used the geranylgeranyltransferase-specific inhibitor GGTI-286 in our 
experiments, which is highly specific for GGTPase1, and is 15 times more potent at inhibiting GTTPase compared to FTPase in vivo [42]. With GGTI-286 we show that the sub-cellular localisation of both Ras85D and DmPDE5/6 is altered upon inhibition of prenyltransferase activity. Drosophila possesses homologues of each mammalian prenyltransferase gene [11], therefore, it is likely that the specificity of prenyltransferase inhibitor action will be conserved between mammal and the fly. Furthermore, work investigating the prenylation of Drosophila Ras, which also has a leucine at its C-terminus, suggests that this protein undergoes modification with a geranylgeranyl group [44].

Mammalian $\mathrm{PrBP} / \delta$ binds to the prenylated, C-terminus of the retinal PDE6 catalytic subunits [51], probably serving to sequester the lipid group from the surrounding solvent [52]. We show here that $D m P D E 5 / 6$ interacts with $D m P r B P / \delta$ when these proteins are expressed in S2 cells (Fig. 4). This is the first demonstration of association of a non-retinal PDE with $\mathrm{PrBP} / \delta$. Indeed, co-expression of $D m \mathrm{PrBP} / \delta$ redirects a large proportion of $D m P D E 5 / 6$ from the plasma membrane to an intracellular location. These data are consistent with the formation of complexes of $D m P r B P / \delta$ and $D m P D E 5 / 6$ where intracellular targeting signals may be compromised in a number of ways. They could be masked, either with the geranylgeranyl group on $D m P D E 5 / 6$ being bound to $D m P r B P / \delta$ or through steric hindrance through protein-protein interaction, which may ablate, compromise or reprogram interactions. Furthermore, if targeting signals remain on each protein then sequestering proteins will serve to compete for the $D m P D E 5 / 6-D m P r B P / \delta$ complex, their efficacy being driven by their concentration and relative affinity.

The Malpighian tubule of Drosophila transports cGMP from the basolateral hemolymph to the lumen [28]. Over-expression of DmPDE5/6 in the tubule principal cell has been shown to inhibit cGMP transport. Despite the altered sub-cellular localisation of C1128S-DmPDE5/6, over-expression of nonprenylated DmPDE5/6 in principal cells also inhibits cGMP transport. This is likely due to the mass of over-expressed C1128S-DmPDE5/6 in the tubule, enabling a biological response in spite of the altered sub-cellular localisation. Alternatively, residual targeting of C1128S-DmPDE5/6 to the apical membrane may account for the inhibition of cGMP transport in these tubules.

The identification here of the first non-retinal cGMP-PDE to undergo prenylation, and the detection of several cGMP-PDEs with CaaX-boxes suggests that prenylation of phosphodiesterases may be more common than previously thought. The molecular characterisation of further putative prenylated cGMP-PDEs will help shed light on the importance of prenylation for cGMP-mediated signaltransduction in non-retinal tissue. Further investigation of DmPDE5/6 function may provide insights into the role of prenylated non-retinal PDEs from other species.

\section{ACKNOWLEDGEMENTS}

This work was supported by the UK Biotechnology and Biological Sciences Council (BB/C00633/1), and the UK Medical Research Council (G8604010).

\section{REFERENCES}

1 Carlisle Michel, J. J., Dodge, K. L., Wong, W., Mayer, N. C., Langeberg, L. K. and Scott, J. D. (2004) PKA-phosphorylation of PDE4D3 facilitates recruitment of the mAKAP signalling complex. Biochem. J. 381, 587-592

2 Schlossmann, J., Feil, R. and Hofmann, F. (2003) Signaling through NO and cGMPdependent protein kinases. Ann. Med. 35, 21-27

3 Zabel, U., Kleinschnitz, C., Oh, P., Nedvetsky, P., Smolenski, A., Muller, H., Kronich, P., Kugler, P., Walter, U., Schnitzer, J. E. and Schmidt, H. H. (2002) Calcium-dependent membrane association sensitizes soluble guanylyl cyclase to nitric oxide. Nat. Cell Biol.

4, 307-311 
4 Willoughby, D. and Cooper, D. M. (2007) Organization and Ca2+ regulation of adenylyl cyclases in cAMP microdomains. Physiol. Rev. 87, 965-1010

5 Conti, M. and Beavo, J. (2007) Biochemistry and physiology of cyclic nucleotide phosphodiesterases: essential components in cyclic nucleotide signaling. Ann. Rev. Biochem. 76, 481-511

6 Baillie, G. S. and Houslay, M. D. (2005) Arrestin times for compartmentalised cAMP signalling and phosphodiesterase-4 enzymes. Curr. Opin. Cell Biol. 17, 129-134

7 Bolger, G. B., Baillie, G. S., Li, X., Lynch, M. J., Herzyk, P., Mohamed, A., Mitchell, L. H., McCahill, A., Hundsrucker, C., Klussmann, E., Adams, D. R. and Houslay, M. D. (2006) Scanning peptide array analyses identify overlapping binding sites for the signalling scaffold proteins, beta-arrestin and RACK1, in cAMP-specific phosphodiesterase PDE4D5. Biochem. J. 398, 23-36

8 Perry, S. J., Baillie, G. S., Kohout, T. A., McPhee, I., Magiera, M. M., Ang, K. L., Miller, W. E., McLean, A. J., Conti, M., Houslay, M. D. and Lefkowitz, R. J. (2002) Targeting of cyclic AMP degradation to beta 2-adrenergic receptors by beta-arrestins. Science 298, 834-836

9 Dodge-Kafka, K. L., Soughayer, J., Pare, G. C., Carlisle Michel, J. J., Langeberg, L. K., Kapiloff, M. S. and Scott, J. D. (2005) The protein kinase A anchoring protein mAKAP coordinates two integrated cAMP effector pathways. Nature 437, 574-578

10 Dodge, K. L., Khouangsathiene, S., Kapiloff, M. S., Mouton, R., Hill, E. V., Houslay, M. D., Langeberg, L. K. and Scott, J. D. (2001) mAKAP assembles a protein kinase A/PDE4 phosphodiesterase cAMP signaling module. Embo J. 20, 1921-1930

11 Maurer-Stroh, S., Washietl, S. and Eisenhaber, F. (2003) Protein prenyltransferases. Genome Biol. 4, 212

12 Resh, M. D. (2004) Membrane targeting of lipid modified signal transduction proteins. Subcell. Biochem. 37, 217-232

13 Willumsen, B. M., Christensen, A., Hubbert, N. L., Papageorge, A. G. and Lowy, D. R. (1984) The p21 ras C-terminus is required for transformation and membrane association. Nature 310, 583-586

14 Maurer-Stroh, S. and Eisenhaber, F. (2005) Refinement and prediction of protein prenylation motifs. Genome Biol. 6, R55

15 Hancock, J. F., Paterson, H. and Marshall, C. J. (1990) A polybasic domain or palmitoylation is required in addition to the CAAX motif to localize p21ras to the plasma membrane. Cell 63, 133-139

16 Anant, J. S., Ong, O. C., Xie, H. Y., Clarke, S., O'Brien, P. J. and Fung, B. K. (1992) In vivo differential prenylation of retinal cyclic GMP phosphodiesterase catalytic subunits. J Biol. Chem. 267, 687-690

17 Qin, N., Pittler, S. J. and Baehr, W. (1992) In vitro isoprenylation and membrane association of mouse rod photoreceptor cGMP phosphodiesterase alpha and beta subunits expressed in bacteria. J. Biol. Chem. 267, 8458-8463

18 Qin, N. and Baehr, W. (1994) Expression and mutagenesis of mouse rod photoreceptor cGMP phosphodiesterase. J. Biol. Chem. 269, 3265-3271

19 Norton, A. W., Hosier, S., Terew, J. M., Li, N., Dhingra, A., Vardi, N., Baehr, W. and Cote, R. H. (2005) Evaluation of the 17-kDa prenyl-binding protein as a regulatory protein for phototransduction in retinal photoreceptors. J. Biol. Chem. 280, 1248-1256 
20 Nancy, V., Callebaut, I., El Marjou, A. and de Gunzburg, J. (2002) The delta subunit of retinal rod cGMP phosphodiesterase regulates the membrane association of Ras and Rap GTPases. J. Biol. Chem. 277, 15076-15084

21 Gillespie, P. G., Prusti, R. K., Apel, E. D. and Beavo, J. A. (1989) A soluble form of bovine rod photoreceptor phosphodiesterase has a novel 15-kDa subunit. J. Biol. Chem. 264, 12187-12193

22 Zhang, H., Li, S., Doan, T., Rieke, F., Detwiler, P. B., Frederick, J. M. and Baehr, W. (2007) Deletion of PrBP/delta impedes transport of GRK1 and PDE6 catalytic subunits to photoreceptor outer segments. Proc. Natl. Acad. Sci. U S A 104, 8857-8862

23 Francis, S. H. and Corbin, J. D. (2005) Phosphodiesterase-5 inhibition: the molecular biology of erectile function and dysfunction. Urol. Clin. North Am. 32, 419-429, vi

24 Cote, R. H. (2004) Characteristics of photoreceptor PDE (PDE6): similarities and differences to PDE5. Int. J. Impot. Res. 16 Suppl 1, S28-33

25 Day, J. P., Dow, J. A., Houslay, M. D. and Davies, S. A. (2005) Cyclic nucleotide phosphodiesterases in Drosophila melanogaster. Biochem. J. 388, 333-342

26 Lugnier, C., Schoeffter, P., Le Bec, A., Strouthou, E. and Stoclet, J. C. (1986) Selective inhibition of cyclic nucleotide phosphodiesterases of human, bovine and rat aorta. Biochem. Pharmacol. 35, 1743-1751

27 Boolell, M., Allen, M. J., Ballard, S. A., Gepi-Attee, S., Muirhead, G. J., Naylor, A. M., Osterloh, I. H. and Gingell, C. (1996) Sildenafil: an orally active type 5 cyclic GMPspecific phosphodiesterase inhibitor for the treatment of penile erectile dysfunction. Int. J. Impot. Res. 8, 47-52

28 Day, J. P., Houslay, M. D. and Davies, S. A. (2006) A novel role for a Drosophila homologue of cGMP-specific phosphodiesterase in the active transport of cGMP. Biochem. J. 393, 481-488

29 Brand, A. H. and Perrimon, N. (1993) Targeted gene expression as a means of altering cell fates and generating dominant phenotypes. Development 118, 401-415

30 Radford, J. C., Davies, S. A. and Dow, J. A. (2002) Systematic G-protein-coupled receptor analysis in Drosophila melanogaster identifies a leucokinin receptor with novel roles. J. Biol. Chem. 277, 38810-38817

31 MacPherson, M. R., Lohmann, S. M. and Davies, S. A. (2004) Analysis of Drosophila cGMP-dependent protein kinases and assessment of their in vivo roles by targetted expression in a renal transporting epithelium. J. Biol. Chem.

32 MacPherson, M. R., Pollock, V. P., Broderick, K. E., Kean, L., O'Connell, F. C., Dow, J. A. and Davies, S. A. (2001) Model organisms: new insights into ion channel and transporter function. L-type calcium channels regulate epithelial fluid transport in Drosophila melanogaster. Am. J. Physiol. Cell Physiol. 280, C394-407

33 Denholm, B., Sudarsan, V., Pasalodos-Sanchez, S., Artero, R., Lawrence, P., Maddrell, S., Baylies, M. and Skaer, H. (2003) Dual origin of the renal tubules in Drosophila: mesodermal cells integrate and polarize to establish secretory function. Curr. Biol. 13, 1052-1057

34 Parker, L., Gross, S. and Alphey, L. (2001) Vectors for the expression of tagged proteins in Drosophila. Biotechniques 31, 1280-1282, 1284, 1286

35 Broderick, K. E., Kean, L., Dow, J. A. T., Pyne, N. J. and Davies, S. A. (2004) Ectopic expression of bovine type 5 phosphodiesterase confers a renal phenotype in Drosophila. J. Biol. Chem. 279, 8159-8168 
36 Rosay, P., Davies, S. A., Yu, Y., Sozen, A., Kaiser, K. and Dow, J. A. (1997) Cell-type specific calcium signalling in a Drosophila epithelium. J. Cell. Sci. 110 ( Pt 15), 16831692

37 MacPherson, M. R., Broderick, K. E., Graham, S., Day, J. P., Houslay, M. D., Dow, J. A. and Davies, S. A. (2004) The dg2 (for) gene confers a renal phenotype in Drosophila by modulation of cGMP-specific phosphodiesterase. J. Exp. Biol. 207, 2769-2776

38 Torrie, L. S., Radford, J. C., Southall, T. D., Kean, L., Dinsmore, A. J., Davies, S. A. and Dow, J. A. (2004) Resolution of the insect ouabain paradox. Proc. Natl. Acad. Sci. U S A

39 Weber, B., Riess, O., Hutchinson, G., Collins, C., Lin, B. Y., Kowbel, D., Andrew, S., Schappert, K. and Hayden, M. R. (1991) Genomic organization and complete sequence of the human gene encoding the beta-subunit of the cGMP phosphodiesterase and its localisation to 4p 16.3. Nucleic Acids Res. 19, 6263-6268

40 Su, Y. H. and Vacquier, V. D. (2006) Cyclic GMP-specific phosphodiesterase-5 regulates motility of sea urchin spermatozoa. Mol. Biol. Cell 17, 114-121

41 Khosravi-Far, R. and Der, C. J. (1995) Prenylation Analysis of Bacterially Expressed and Insect Cell-Expressed Ras and Ras-Related Proteins. In Small GTPases and Their Regulators (Balch, W. E., Der, C. J. and Hall, A., eds.), pp. 46-59, Academic Press, London

42 Lerner, E. C., Qian, Y., Hamilton, A. D. and Sebti, S. M. (1995) Disruption of oncogenic K-Ras4B processing and signaling by a potent geranylgeranyltransferase I inhibitor. J. Biol. Chem. 270, 26770-26773

43 Hancock, J. F., Magee, A. I., Childs, J. E. and Marshall, C. J. (1989) All ras proteins are polyisoprenylated but only some are palmitoylated. Cell 57, 1167-1177

44 Kauffmann, R. C., Qian, Y., Vogt, A., Sebti, S. M., Hamilton, A. D. and Carthew, R. W. (1995) Activated Drosophila Ras1 is selectively suppressed by isoprenyl transferase inhibitors. Proc. Natl. Acad. Sci. U S A 92, 10919-10923

45 Houslay, M. D. and Adams, D. R. (2003) PDE4 cAMP phosphodiesterases: modular enzymes that orchestrate signalling cross-talk, desensitization and compartmentalization. Biochem. J. 370, 1-18

46 Houslay, M. D., Baillie, G. S. and Maurice, D. H. (2007) cAMP-Specific phosphodiesterase-4 enzymes in the cardiovascular system: a molecular toolbox for generating compartmentalized cAMP signaling. Circ. Res. 100, 950-966

47 Resh, M. D. (2006) Trafficking and signaling by fatty-acylated and prenylated proteins. Nat. Chem. Biol. 2, 584-590

48 Jiang, X., Benovic, J. L. and Wedegaertner, P. B. (2007) Plasma membrane and nuclear localization of $G$ protein coupled receptor kinase 6A. Mol. Biol. Cell 18, 2960-2969

49 Smith, K. J., Baillie, G. S., Hyde, E. I., Li, X., Houslay, T. M., McCahill, A., Dunlop, A. J., Bolger, G. B., Klussmann, E., Adams, D. R. and Houslay, M. D. (2007) (1)H NMR structural and functional characterisation of a cAMP-specific phosphodiesterase-4D5 (PDE4D5) N-terminal region peptide that disrupts PDE4D5 interaction with the signalling scaffold proteins, betaarrestin and RACK1. Cell. Signal. 19, 2612-2624

50 Moores, S. L., Schaber, M. D., Mosser, S. D., Rands, E., O'Hara, M. B., Garsky, V. M., Marshall, M. S., Pompliano, D. L. and Gibbs, J. B. (1991) Sequence dependence of protein isoprenylation. J. Biol. Chem. 266, 14603-14610 
51 Cook, T. A., Ghomashchi, F., Gelb, M. H., Florio, S. K. and Beavo, J. A. (2000) Binding of the delta subunit to rod phosphodiesterase catalytic subunits requires methylated, prenylated C-termini of the catalytic subunits. Biochemistry 39, 13516-13523

52 Hanzal-Bayer, M., Renault, L., Roversi, P., Wittinghofer, A. and Hillig, R. C. (2002) The complex of Arl2-GTP and PDE delta: from structure to function. Embo J. 21, 2095-2106 


\section{FIGURE LEGENDS}

Table 1. Sequence identity (similarity) between cGMP-PDEs with putative prenylation motifs and Human PDE5A1, Human PDE11A4 and DmPDE5/6.

Fig. 1. CaaX-box prenylation motifs occur in non-retinal cGMP-PDEs from non-mammalian classes. cGMP-PDE sequences containing putative CaaX-box prenylation motifs were identified using BLAST-searching of the non-redundant protein database with DmPDE5/6 as the query sequence. Protein sequences were aligned and sequence similarity tree was generated using ClustalW (http://www.ebi.ac.uk/Tools/clustalw/) [46]. A. Alignment of the C-terminal 25 amino acids of CaaX-box cGMP-PDEs (highlighted in red) and DmRas85D, showing conserved CaaX-box cysteine residue, shaded black. B. Sequence similarity tree of cGMP-PDEs with CaaX-box prenylation motifs (highlighted in red) with human PDE5A1, human PDE11A4 and human retinal PDE catalytic subunits as reference sequences.

Fig. 2. DmPDE5/6 is prenylated at a C-terminal CaaX-box. A. Western analysis of $\left[{ }^{3} \mathrm{H}\right] \mathrm{MVA}$ labelled Sf9 cells expressing wild-type DmPDE5/6 (WT), C1128S-DmPDE5/6 (CS) or uninfected control cells (CON). Either $10 \mu \mathrm{g}$ of total lysate (lanes 1-3) or DmPDE5/6 immunoprecipitated with a rabbit polyclonal anti-DmPDE5/6 antibody, [14] (lanes 4-6) were analysed. B. Fluorograph of samples shown in panel A, lanes denoted as in A. Positive bands for DmPDE5/6 and C1128SDmPDE5/6 are observed at $130 \mathrm{kDa}$. C. Comparison of the Michaelis-Menton plots for cG-PDE activity of DmPDE5/6 and C1128S-DmPDE5/6 expressed in Sf9 cells. Equal relative amounts, as ascertained by western blotting, of either DmPDE5/6 (triangles) or C1128S-DmPDE5/6 (squares) were assayed for cGMP-PDE activity, $\mathrm{nmol} \mathrm{cGMP} / \mathrm{mg} / \mathrm{min} \pm$ S.E.M, $N=3$.

Fig. 3. Plasma membrane association of DmPDE5/6 and Ras85D in S2 cells is affected by prenylation

A, B, D: Plasmids encoding wild-type DmPDE5/6 (A), C1128S mutation of DmPDE5/6 (B) and GFP-tagged Ras85D (D) were expressed in S2 cells. DmPDE5/6 and C1128S-DmPDE5/6 were localised with anti-V5 antibody using confocal microscopy. C, E. Transfected cells were also treated with the prenylation inhibitor GGTI-286, transfected with DmPDE5/6 (C) and GFPtagged Ras85D (E) and the expressed protein visualised accordingly. Control (untransfected) cells did not show staining with anti-V5 antibody (not shown). In all panels, single cells are shown in which cell nuclei were stained with DAPI (blue). Scale bars in all images correspond to $5 \mu \mathrm{m}$.

A-E, Insets: Cell fractionation and Western blotting of DmPDE5/6 and C1128S-DmPDE5/6 using anti-V5 antibody (130 kDa) and of GFP:Ras85D (50 kDa) using anti-GFP antibody. Fractions assayed for presence of expressed protein were: P15 and S15 as described in Materials and Methods.

Fig. 4. DmPDE5/6 interacts with $D m P r B P / \delta$

A. Localisation of $\mathrm{C}$-terminal V5-tagged $D m \mathrm{PrBP} / \delta$ expressed in $\mathrm{S} 2$ cells B. S2 cells were transiently co-transfected with V5-tagged $D m P r B P / \delta$ (red) and GFP:DmPDE5/6 (green), stained with anti-V5 antibody and DAPI (blue) and viewed by confocal microscopy. i. GFP:DmPDE5/6; ii. $D m P r B P / \delta$; iii. Merge of GFP:DmPDE5/6 with $D m P r B P / \delta$ showing co-localisation (yellow). C. Co-immunoprecipitation of $D m P D E 5 / 6$ with $D m P r B P / \delta$. S2 cells were transiently transfected with $D m P D E 5 / 6$ and $D m P r B P / \delta$, or with $D m P r B P / \delta$ on its own. Cell lysates were subjected to western blotting to confirm expression of constructs (bottom two panels) and DmPDE5/6 was immunoprecipitated using an anti-DmPDE5/6 poly clonal antibody. Western analysis confirms DmPDE6 was precipitated (second panel) whereas top panel shows that $D m P r B P / \delta$ coprecipitates with DmPDE5/6. 
Fig. 5. Altered sub-cellular localisation of $D m P D E 5 / 6$ in response to $D m P r B P / \delta$ expression A. S2 cells were transfected with V5-tagged $D m P D E 5 / 6$ and/or $D m P r B P / \delta$, lysed and separated into sub-cellular fractions using variable centrifugation. B. Western blot of fractionated V5tagged DmPDE5/6. C. Western blot of fractionated V5-tagged $D m P r B P / \delta$. D. Western blot of fractionated DmPDE5/6 co-expressed with $D m P r B P / \delta$.

Fig. 6. Mis-localisation of C1128S-DmPDE5/6 in a polarised epithelium.

The transgenic UAS-GFP: C1128S-DmPDE5/6 line was generated and crossed to the principalcell specific c42 driver. Tubules from adult progeny were dissected, stained for the apical membrane marker F-actin using phalloidin; and counterstained with the nuclear stain DAPI, 4', 6'diamidino-2-phenylindole hydrochloride. A. c42/GFP: C1128S-DmPDE5/6 B. for comparison, staining in c42/GFP:DmPDE5/6 transgenic tubules [17] is shown. Scale bars are $10 \mu \mathrm{m}$; tubule diameter can be taken as $35 \mu \mathrm{m}$. In panels $\mathrm{A}$ and $\mathrm{B}$, green fluorescence denotes GFP-tagged C1128S-DmPDE5/6 (A, apical staining indicated by white arrows; cytoplasmic staining indicated by yellow arrow) or GFP-tagged DmPDE5/6 (B, apical staining indicated by white arrows, basolateral staining indicated by blue arrow); F-actin is stained red, and nuclei stained blue. No GFP signal was observed in either parental c42 or UAS tubules (data not shown). C. The C1128S-DmPDE5/6 transgene encodes active cG-PDE enzyme in tubules. Measurements of cGPDE activity in tubules from c42, UAS-GFP: C1128S-DmPDE5/6, c42/UAS-GFP: DmPDE5/6 C1128S are shown. For clarity, data for cG-PDE activity in tubules of UAS-GFP:DmPDE5/6, c42/UAS-GFP:DmPDE5/6 [17] are included. Data are expressed as mean cG-PDE activity, (pmol cGMP/min/mg protein) \pm SEM, $N=3-6$. Significance (compared to parental lines) denoted by *, $\mathrm{p}<0.05$, Student's $t$-test. D. Western blot of GFP:C1128S-DmPDE5/6 and GFP:DmPDE5/6 expressed in principal-cells using anti-GFP antibody (top panel). Loading control using anti- $\gamma$ tubulin antibody (lower panel). E. Rates of cGMP transport for UAS-GFP:C1128S-DmPDE5/6 and c42/UAS-GFP:C1128S-DmPDE5/6 tubules are shown. F. cGMP transport ratio, where active transport is defined as a ratio of more than 1, in UAS-GFP:C1128S-DmPDE5/6 and c42/UASGFP:C1128S-DmPDE5/6 tubules. G. Rates of cGMP transport for UAS-GFP:DmPDE5/6 and c42/UAS-GFP:DmPDE5/6 tubules. H. cGMP transport ratios for UAS-GFP:DmPDE5/6 and c42/UAS-GFP:DmPDE5/6 tubules. cGMP transport rate data are expressed as $\mathrm{pmol}$ cGMP/min \pm SEM, $N=12$. Transport ratio expressed \pm SEM, $N=12$. Significance denoted by $*, p<0.05$, Student's $t$-test.

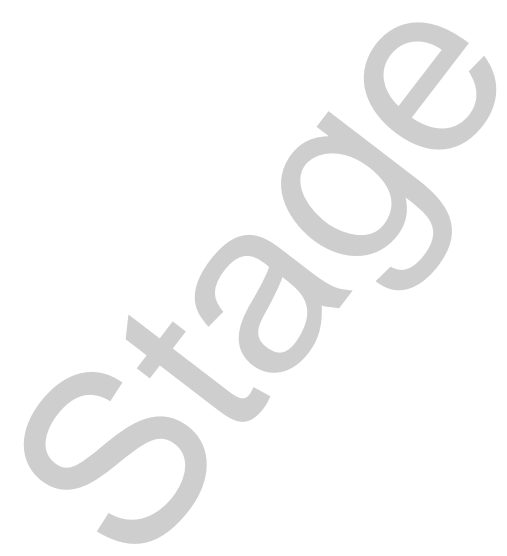




\begin{tabular}{|c|c|c|c|c|c|c|}
\hline \multirow[t]{2}{*}{ Protein } & \multirow{2}{*}{$\begin{array}{l}\text { Percentage } \\
\text { identities } \\
\text { (similarities) } \\
\text { with } \\
\text { HsPDE5A1 }\end{array}$} & \multirow{2}{*}{$\begin{array}{l}\text { Percentage } \\
\text { identities } \\
\text { (similarities) } \\
\text { with } \\
\text { HsPDE11A4 }\end{array}$} & \multirow{2}{*}{$\begin{array}{l}\text { Percentage } \\
\text { identities } \\
\text { (similarities) } \\
\text { with } \\
\text { HsPDE6B }\end{array}$} & \multirow{2}{*}{$\begin{array}{l}\text { Percentage } \\
\text { identities } \\
\text { (similarities) } \\
\text { with } \\
\text { DmPDE5/6 }\end{array}$} & \multicolumn{2}{|c|}{$\begin{array}{c}\text { PrePS } \\
\text { (http://mendel.imp.univie.ac.at/sat/ } \\
\text { PrePS) score }\end{array}$} \\
\hline & & & & & $\begin{array}{l}\text { Farnesyl } \\
\text { transferase }\end{array}$ & $\begin{array}{l}\text { Geranylgeranyl } \\
\text { transferase } 1\end{array}$ \\
\hline $\begin{array}{l}\text { D. melanogaster } \\
\text { PDE } 5 / 6\end{array}$ & $30(14)$ & 31 (13) & $23(15)$ & & -0.262 & +1.551 \\
\hline $\begin{array}{l}\text { D. pseudoobscura } \\
\text { GA20950 }\end{array}$ & $30(14)$ & $30(14)$ & $23(15)$ & $88(3)$ & -0.386 & +1.200 \\
\hline $\begin{array}{l}\text { A. gambiae } \\
\text { AGAP004119 }\end{array}$ & 34 (16) & 34 (16) & 25 (17) & $62(9)$ & -0.982 & +0.260 \\
\hline $\begin{array}{l}\text { A. mellifera } \\
\text { XP_394107 }\end{array}$ & 34 (16) & 34 (14) & $28(16)$ & 57 (10) & -0.402 & -1.128 \\
\hline $\begin{array}{l}\text { T. castaneum } \\
\text { XP_967847 }\end{array}$ & 36 (14) & 36 (15) & 29 (18) & 55 (11) & -0.720 & +2.606 \\
\hline $\begin{array}{l}\text { S. purpuratus } \\
\text { PDE5 }\end{array}$ & $36(16)$ & $36(16)$ & $29(17)$ & 39 (14) & -0.170 & -0.776 \\
\hline $\begin{array}{l}\text { D. rerio } \\
\text { XP_697567 }\end{array}$ & 35 (18) & $71(9)$ & $28(17)$ & $30(15)$ & -4.786 & -17.436 \\
\hline $\begin{array}{l}\text { X. tropicalis } \\
\text { PDE5a }\end{array}$ & $75(9)$ & 33 (18) & $28(20)$ & $31(13)$ & -7.757 & -20.246 \\
\hline
\end{tabular}

Table 1.

Licenced copy. Copying is not permitted, except with prior permission and as allowed by law. 
A

D. melanogaster PDE5/6

D. pseudoobscura GA20950

A. gambiae AGAP004119

A. mellifera XP_394107

S. purpuratus $\mathrm{PDE} 5$

T. castaneum XP_967847

D. rerio XP_697567

$\mathrm{X}$. tropicalis PDE5a

H. sapiens PDE6B

D. melanogaster Ras $85 \mathrm{D}$
S S S T S A GGQMVDKS - KKR S K LCA L L

S S S T S SAG - TVVDKS - KKRSKLCSL L - - G T DQHHE QAMS H P PKKR S K LCML L P E DAAKS TKA L I P DR - K S R K LCL L I G S QMS QQCKEA LAAK- - KNKS S L C S V I - A P A C Q Q P P L GHKLKRNKHKLC C I L - EGSTHGVEPKQT PVANYKEGACCGH - I LAEQQEKNLVNGAK-SQPEVKCNMD - VAAKKVGTEI CNGGP-APKS S TCCI L - KDKDNKGRRGRKMNK - P NRR F K KML

B

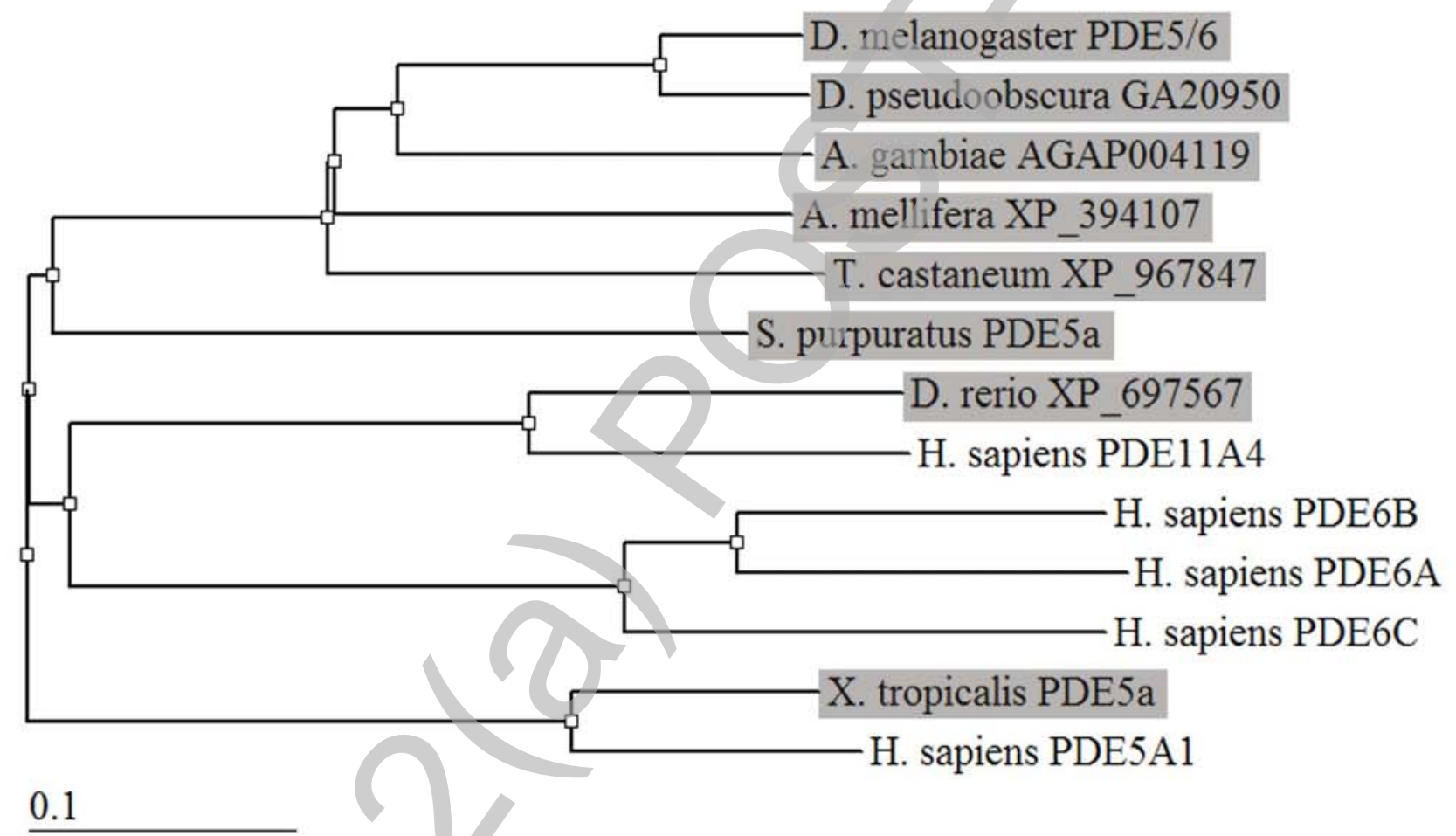




\section{Figure 2}

A

Anti-V5 Western blot

Total lysate Immunoprecipitate

WT CS CON WT CS CON

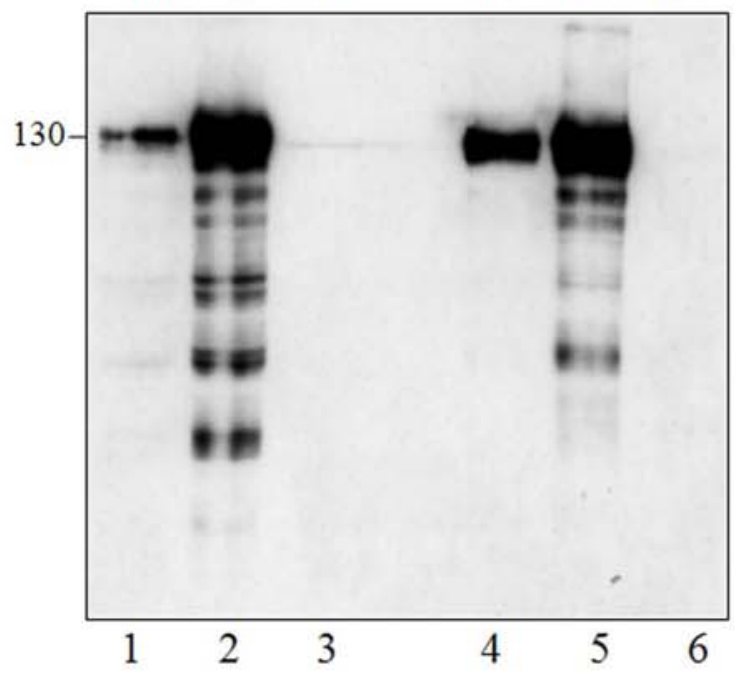

B

Fluorograph Total lysate Immunoprecipitate WT CS CON WT CS CON

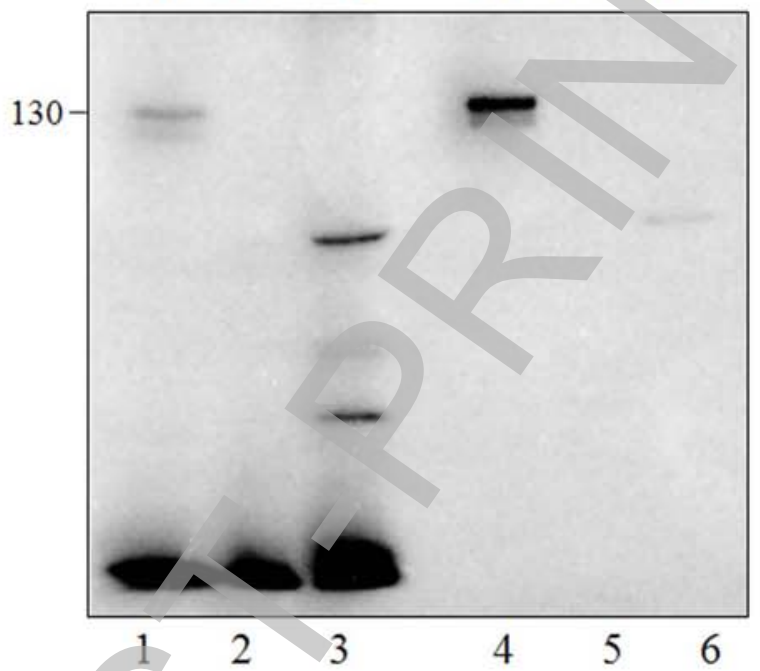

C

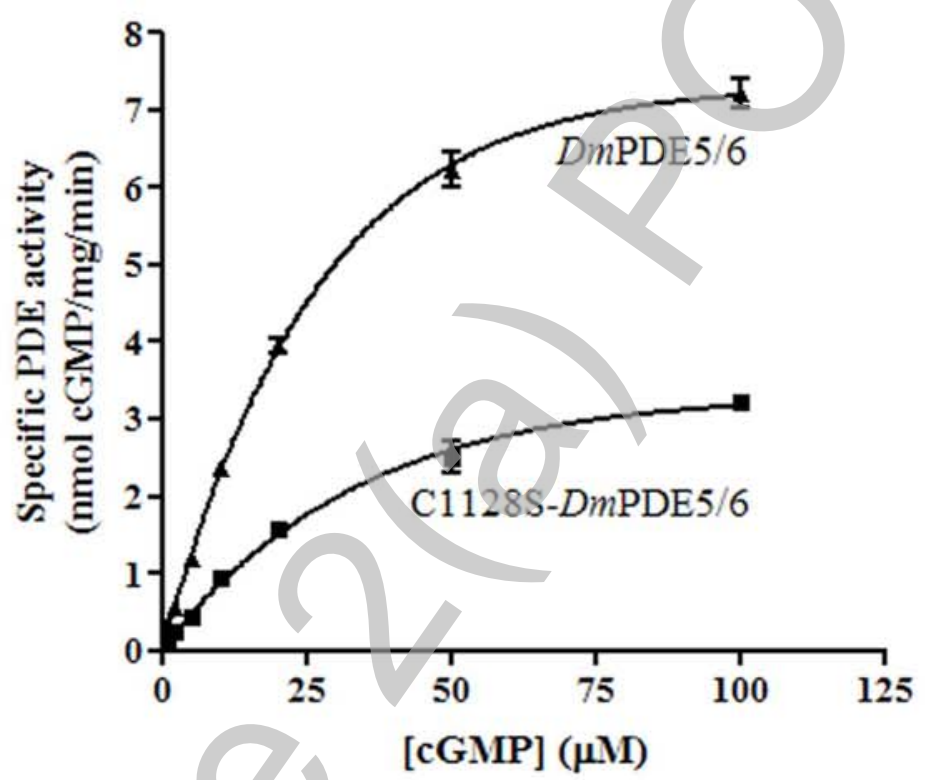

Licenced copy. Copying is not permitted, except with prior permission and as allowed by law. (C) 2008 The Authors Journal compilation (C) 2008 Biochemical Society 
Figure 3

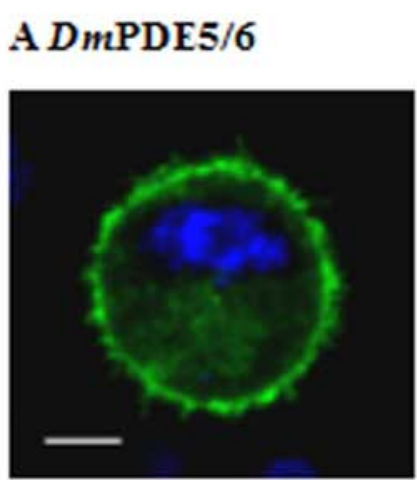

\section{B C1128S-DmPDE5/6 C $D m P D E 5 / 6+$ GGTI}
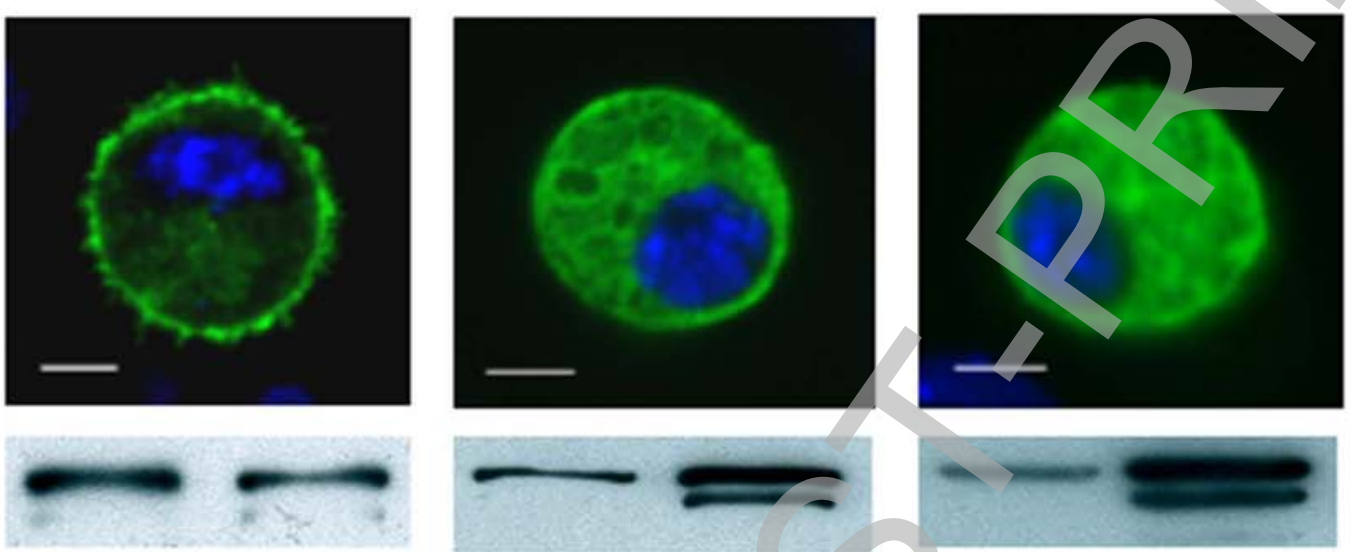

P15

$\mathrm{S} 15$
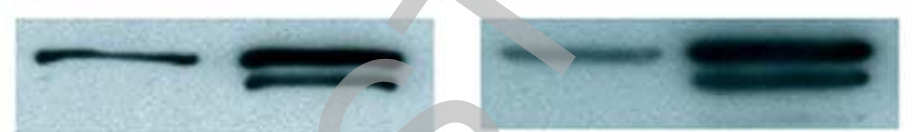

\section{Ras85D}
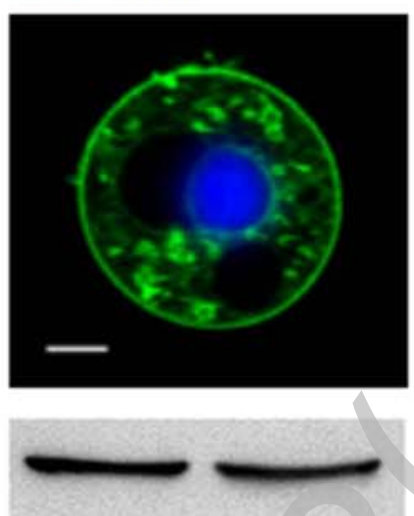

P15 $\mathrm{S} 15$

P15

$\mathrm{S} 15$ 
Figure 4

A $D m \operatorname{PrBP} / \delta$
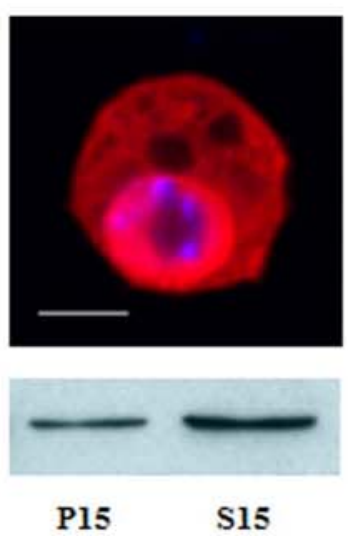

Bi $D m P D E 5 / 6$

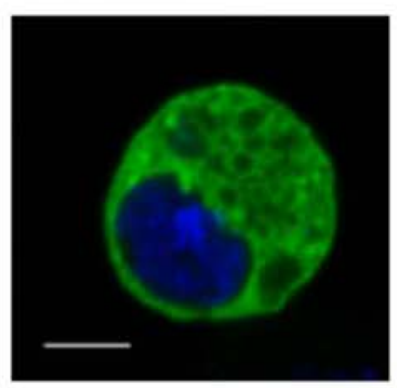

ii $D m P r B P$

iii Merge
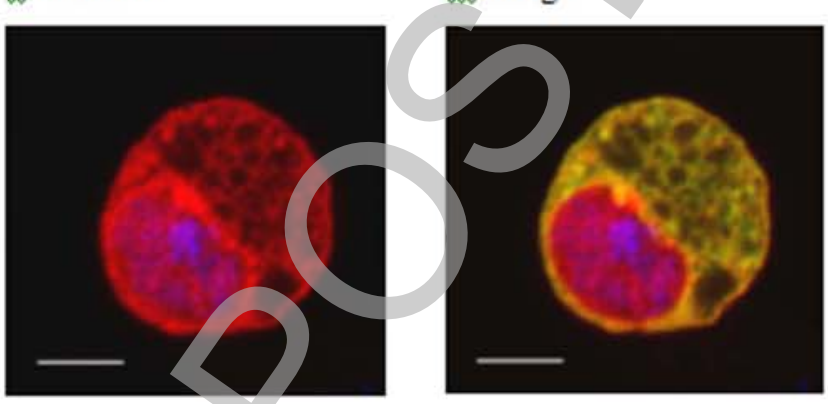

C

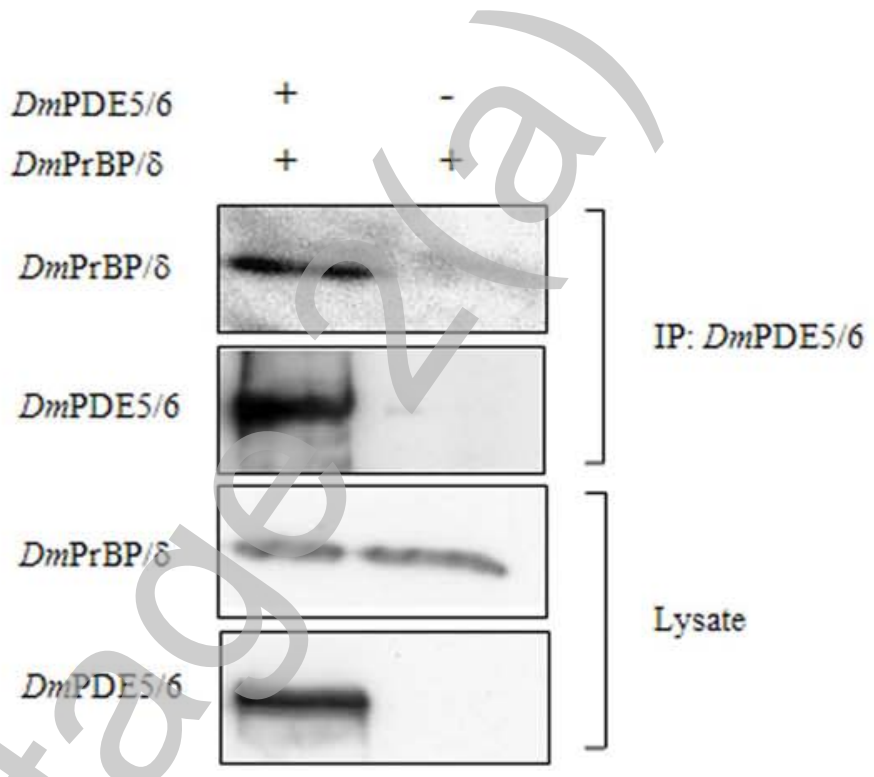

Licenced copy. Copying is not permitted, except with prior permission and as allowed by law. (C) 2008 The Authors Journal compilation (c) 2008 Biochemical Society 
Figure 5

A Homogenate

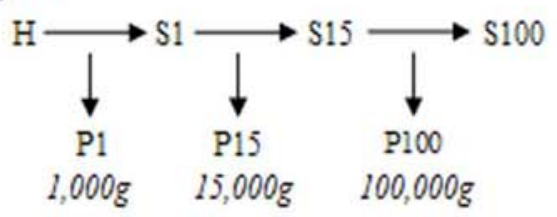

B DmPDE5/6 expressed alone

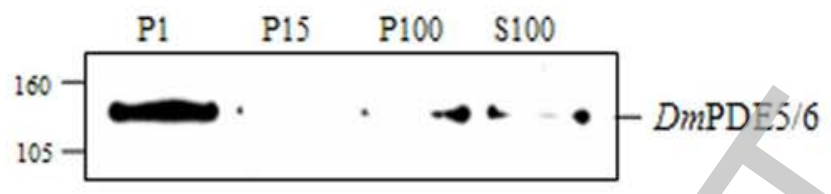

C

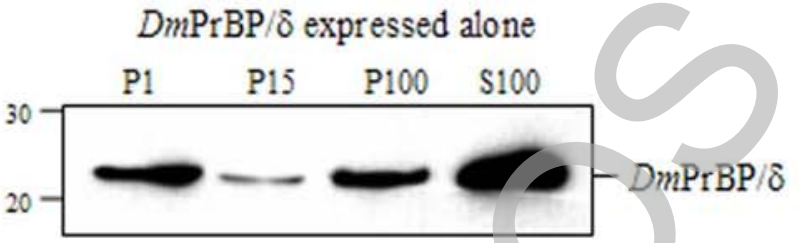

D

DmPDE5/6 co-expressed with DmPrBP/8

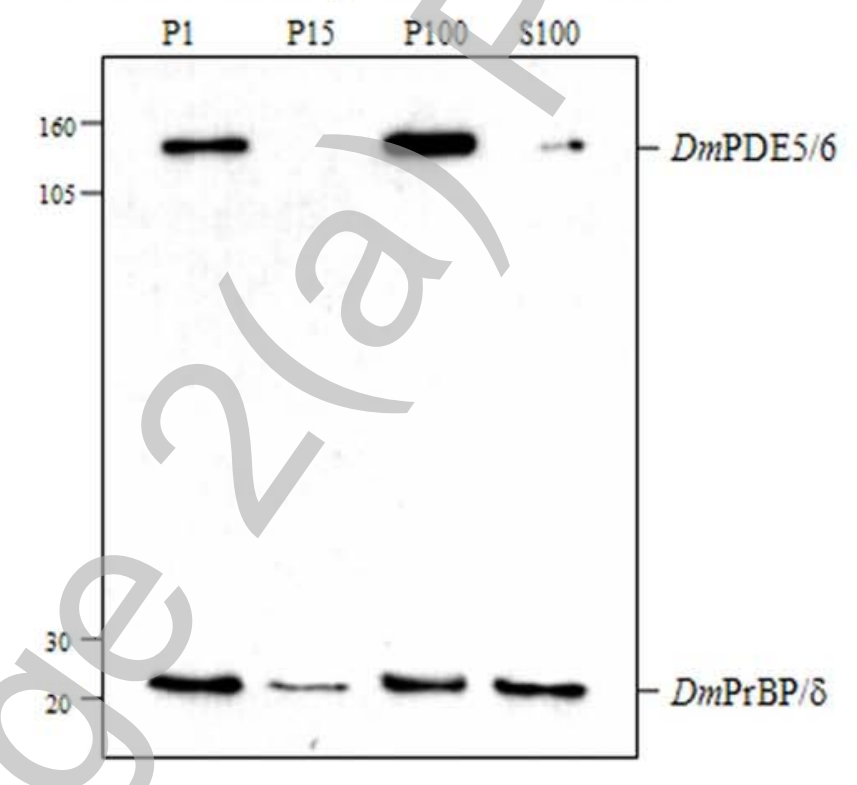

Licenced copy. Copying is not permitted, except with prior permission and as allowed by law. (C) 2008 The Authors Journal compilation (C) 2008 Biochemical Society 


\section{A Targeted GFP:C1128S DmPDE5/6}

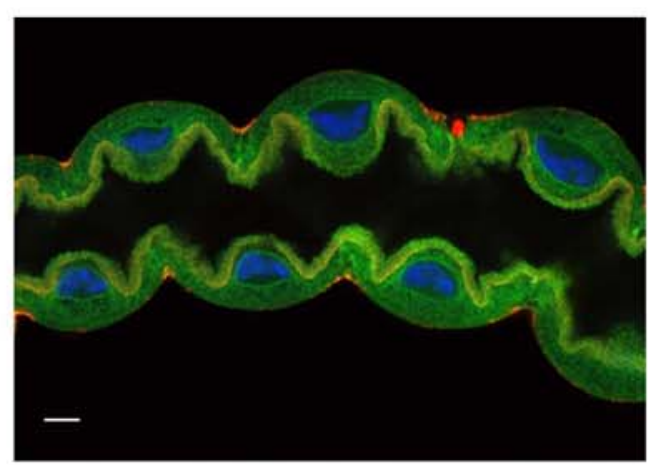

C Tubule cGMP-PDE activity

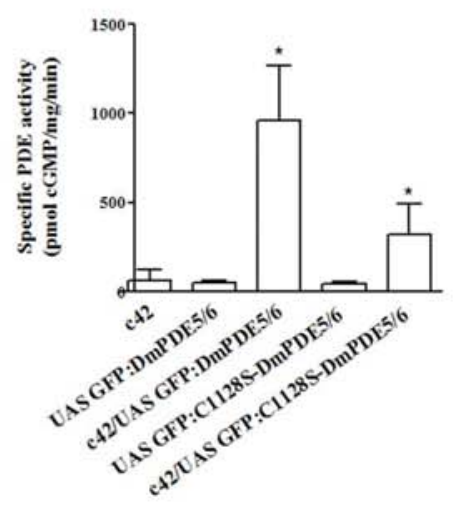

E cGMP transport rate C1128S DmPDE5/6

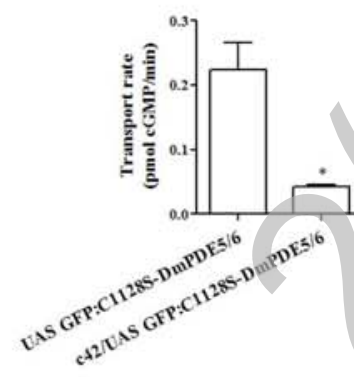

G cGMP transport rate - DmPDE5/6
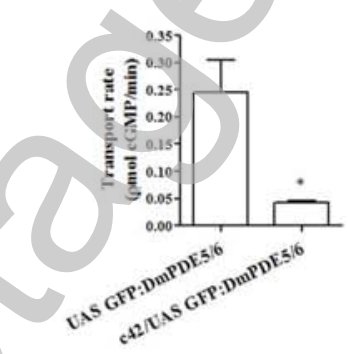

B Targeted GFP :DmPDE5/6

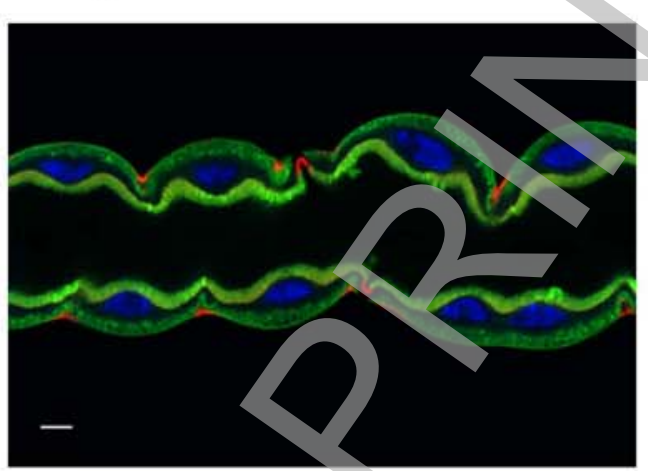

D Western blot of GFP-tagged DmPDE5/6
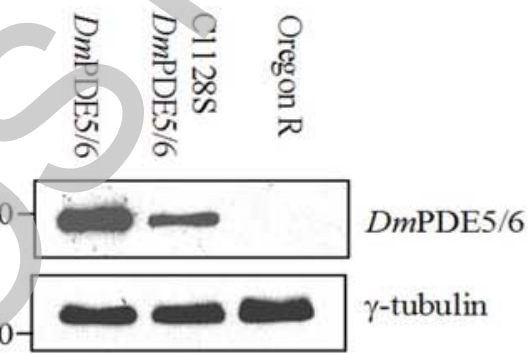

F cGMP transport ratio C1128S DmPDE5/6

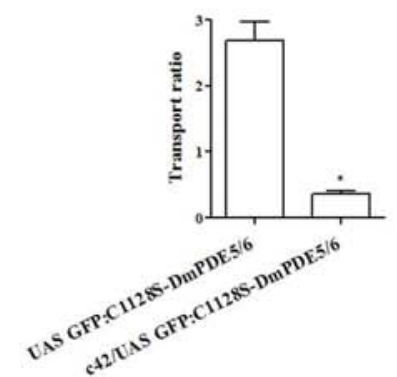

H cGMP transport ratio - DmPDE5/6

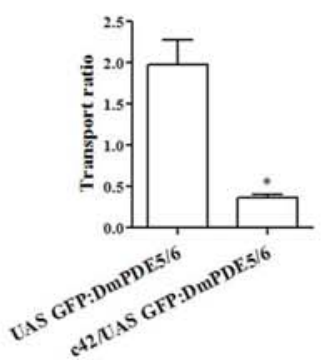

